368

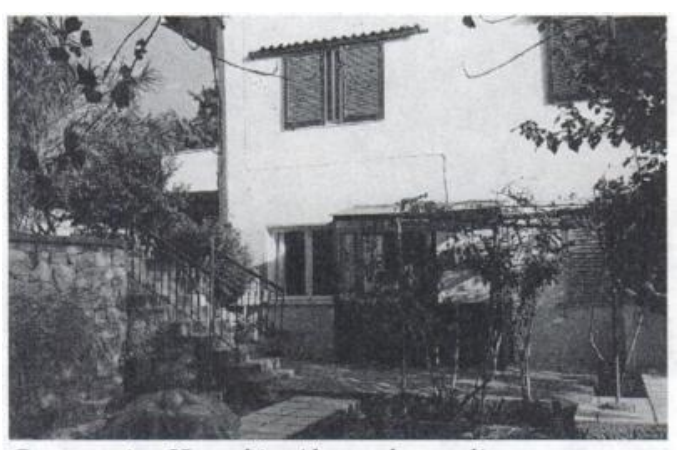

Community Hostel in Alexandroupolis

available in Greece to train people in current approaches to mental health care, and is attended by about 100 trainees.

\section{Comments}

The mental health system in this part of rural Greece provides a fascinating model of social and community psychiatry. This area was lacking any psychiatric services until recently, with available options being either some sort of private care, or in-patient treatment, quite likely resulting in long stay admission in a hospital miles away in the city of Thessaloniki. With the establishment of the Democrition University Medical School and financial help from the EC, Thrace now enjoys an advanced, quality service system based on the current philosophy of community care, and is indisputably cost-effective. The monitoring of the service has provided convincing evidence, although the state bureaucrats have yet to be convinced, that the cost per individual case in the community residential facilities is less than $50 \%$ of the cost in a long stay mental hospital. This is of particular importance for a Mediterranean country without strategic planning for mental health, as this depends on the political ideology of the party in power. There is an admirable enthusiasm and commitment from all members of staff, led by Professor P. Sakellaropoulos, a French trained psychoanalyst-psychiatrist with a dedication to community care. He and his colleagues are proud to have contributed to the "reforms" of mental health care in Greece. They are, however, fully aware of the difficulties experienced at present by long established health care systems in the West. Their concern is that mental health care may already be in an "anti-reform" trend, which will certainly have an effect on them. A point to be taken into consideration is that any innovations in psychiatry, unless they are supported by vigorous research, become vulnerable. Some recent examples are the therapeutic community and the Italian psychiatric reforms. Research has become necessary even for the politics of survival!

\title{
Appeal from the former Yugoslavia
}

Professor Dusan Kecmanovic, Professor of Psychiatry, University of Sarajevo, has had to flee Sarajevo and is seeking a job in a psychiatric hospital in London. It would be appreciated if anyone who is able to help him would contact him at 11000 Beograd, Ohrdiska 2A, Yugoslavia. 